Atmosphere," "Glaciers," "The Work of Underground Water," "The Soil," and "The Rocks and their Order." Closer examination, however, shows that these headings are texts for exposition rather than descriptive titles, and a great variety of unexpected information is brought out in the course of the discussions, which are not cramped by an undue effort after conciseness of expression. Thus the Stellar Realm includes a description of the solar system, in which, incidentally, the fact that a planet always keeps the same face turned towards the body around which it revolves, is implied to prove that it does not rotate on its axis. The chapter on the Atmosphere embraces almost as much as the atmosphere itself: not only a little on climate and a great deal on storms, but all that is said about the oceans, tides, lakes and rivers is included under this head; yet glaciers have a chapter to themselves. The greater part of the "Work of Underground Water" is devoted to the phenomena of volcanoes, while earthquakes are dealt with apart under "The Rocks and their Order," a chapter which also includes a section on the moon.

The whole is written in a thoroughly interesting style, like all Prof. Shaler's work, and the frequent references to his own researches give it an element of personal attractiveness. He mentions that, in spite of his long study of swamps, he never saw the phenomenon known as Will-o'-the-Wisp, and is inclined to disbelieve in its existence ; the reports of a moving light being, in his opinion, due to subjective impressions induced by gazing into darkness.

But although an interesting book to read, and one which is likely to attract the reader to more systematic scientific studies, this work seems to leave an opportunity for honest doubt as to the wisdom of piecing together portions of discussions unequal in degree of detail with the object of showing the uniformity and continuity of natural processes. There is a want of some more definite coordinating idea, such as would be supplied by considering the progressive evolution of the world and its processes from the condition of a raw planet up to its completion as the home of man. H. R. M.

Admiral Sir William Robert Mends, G.C.B. By

Bowen Stilon Mends. Pp. xvi +380 . (London: John Murray, Albemarle Street, I899.)

THIS biography is of special interest, as the life of Admiral Sir William Mends was exceptionally active and eventful. The facts are taken chiefly from his diary, and from letters to his wife; and his detailed account of the months he spent in the Crimea during the war, gives a good idea of the difficulties which had to be contended with at the time. The author was evidently keenly alive to the scientific side of his profession, for he states that, so far back as 1830 , the young midshipmen on board the Thetis had to make daily reckonings of the latitude by star altitudes, and of the longitude by lunar observations. The admirable descriptions which he gives of the ships, afford us an excellent opportunity of noting the advance which has been made in the navy, and the new scientific applications which have been continuously introduced.

The Great Salt Lake Trail. By Colonel H. Inman

and Colonel W. F. Cody. Pp. xiii + 529. (New

York: The Macmillan Company, I898.)

THIS book is of great interest, but of little or no scientific importance. It is a valuable contribution to the history of early travel in North America, and comprises stories related by members of the first exploring and trapping expeditions. The remarkable adventures of "Buffalo Bill," one of the authors, are also described.

We feel, on finishing the book, that we have obtained a great deal of information, and a good insight into the gradual and steady growth of civilisation in the part of the United States with which it deals.

No. I 539, vOL. 59]
LETTERS TO THE EDITOR.

[The Editor does not hold himself responsible for opinions ex. pressed by his correspondents. Neither can he undertake to return, or to correspond with the writers of, rejected manuscripts intended for this or any other part of NATURE. No notice is taken of anonymous communications.]

\section{The Interferometer.}

As I have been away from home, I have only to-day seen Lord Rayleigh's letter on the interferometer, in your issue of April 6, and I write at once to state that I agree heartily with all he says. I am quite confident that the "structure" discovered by Prof. Michelson in the spectral lines is a real one existing in the light emitted by the source, and I hold this opinion after a careful study of Prof. Michelson's work, com. bined with the fact that all the "structure" revealed by the interferometer in the light emitted by a source placed in a strong magnetic field is in general accord with my own observations with a $2 \mathrm{I}^{\circ} 5$ feet grating.

The law deduced by Prof. Michelson, from his observations with the interferometer, for the amount of the magnetic (Zeeman) effect, viz. that "it is approximately the same for all colours and all substances," was, however, at such utter variance with all observations made with a good grating, that I felt bound to question the general performance of an instrument which yielded such a law. My opposition was directed against this law, and if the interferometer had insisted on it, then the interferometer must be discarded as a measuring instrument, or be standardised according to some other scheme.

I am very glad, however, to hear from Prof. Michelson that the law announced by him was probably generalised from insufficient data, and that the interferometer is not at fault. This being conceded, and the law being abandoned, I am thoroughly satisfied, and my confidence in the instrument is reestablished.

I may just add that the question as to whether the working of the instrument is prejudiced by "diffraction" or not, was not raised by me, but by others; nor did I intend for a moment to support the idea that the phenomena were due to diffraction. The main phenomena revealed are certainly not due to diffraction, and it is not easy to see where diffraction can come in. The light, of course, passes through a slit, and through other pieces of optical apparatus; and I thought it just possible that some of the minor effects-some of the little "humps," perhaps, in Prof. Michelson's drawings-might be due to transmission through the slit or other pieces of apparatus. It is very easy to determine, however, if diffraction plays any part, for the effects due to it should be similar for all wave-lengths, and should therefore attend all spectral lines varying merely in scale for the different wave-lengths. It is hardly necessary, however, to mention this obvious fact, and I am sure it has been duly taken into account long ago by Prof. Michelson.

Bardowie, Orwell Park, Dublin, April 2 I.

$$
\text { Thomas PReston. }
$$

\section{Absolute Determination of the Ohm.}

THE recent great advances in methods of calculating coefficients of mutual and self-induction, due to Prof. Jones and his colleagues in the work, has suggested that a method, which occurred to me some years ago, for the absolute determination of resistance might now be employed with, I think, some ad. vantages over even the Lorentz method. It is as follows :Take an earth inductor coil, fixed so that it can revolve continuously, thus giving a pure sine voltage, due to cutting the lines of the earth's magnetic field. Take the coils made by the Committee fur the determination of the ampere, as described by Prof. Ayrton, and use the two outside coils as the primary and the inside coil as the secondary of a transformer. Pass the current from the earth inductor through one set of coils of a Kelvin balance, and thence through the primary of the transformer. Then through the (non-inductive or easily calculated inductive) resistance required to be measured, thence back to the earth inductor. Connect the secondary of the transformer to the other set of coils of the Kelvin balance, and speed up the earth inductor till the Kelvin balance arm becomes horizontal, and the pull on the two sets of coils is equal. Then take out the resistance we are measuring, and speed up the inductor till the Kelvin balance comes to zero again. 